\title{
The lac operator-repressor system is functional in the mouse
}

\author{
Carolyn A. Cronin, Wendy Gluba, and Heidi Scrable ${ }^{1}$ \\ Department of Neuroscience, University of Virginia, Charlottesville, Virginia 22908, USA
}

\begin{abstract}
We report the successful transfer of a fully functional lac operator-repressor gene regulatory system to the mouse. The key component is a lac repressor transgene that resembles a typical mammalian gene both in codon usage and structure and expresses functional levels of repressor protein in the animal. We used the repressor to regulate the expression of a mammalian reporter gene consisting of the tyrosinase promoter embedded with three short lac operator sequences and the tyrosinase coding sequence. Pigmentation of the mouse was controlled by the interaction of the lac repressor with the regulatable Tyrosinase transgene in a manner that was fully reversible by the lactose analog IPTG. Direct control of mammalian promoters by the lac repressor provides tight, reversible regulation, predictable levels of de-repressed expression, and the promise of reversible control of the endogenous genome.
\end{abstract}

[Key Words: lac repressor; gene regulation; transgenic mice; tyrosinase; pigmentation; albino]

Received February 27, 2001; revised version accepted April 25, 2001.

The mouse is the most widely used experimental animal to model mammalian development and disease. In recent years, technological advances in genetic manipulation of the mouse genome have made it even more valuable as a research tool, and a great deal of information has been learned from conventional knockout and transgenic experiments. Despite this, it can be difficult to draw definite conclusions from these studies. Embryonic lethality might preclude the possibility of analyzing adult phenotype, or activation of compensatory systems confuse the analysis. Tight, reversible control of gene expression would greatly broaden the possible experimental questions that can be addressed. To gain such control, the ideal system would enable a target gene to be switched on and off repeatedly, without affecting the expression of nontargeted genes. With this ideal in mind, we have developed the lac repressor regulatory system for use in the mouse.

The lac operon of Escherichia coli consists of a set of genes coordinately regulated by lactose (Jacob and Monod 1961). The regulatory components of the system are the lac repressor and its DNA-binding sequence, the lac operator. In the absence of lactose, lac repressor occupies the lac operators and prevents transcription. Lactose causes a conformational change in the repressor, and it vacates the operators, allowing RNA polymerase to gain access to the promoter and initiate transcription.

$\mathrm{Hu}$ and Davidson (1987) were the first to use lac elements to control reporter-gene expression reversibly in

${ }^{1}$ Corresponding author.

E-MAIL hs2n@virginia.edu; FAX (804) 982-4380.

Article and publication are at http://www.genesdev.org/cgi/doi/10.1101/ gad.892001. mammalian cells. Their results were extended by Figge et al. (1988), who demonstrated that the lac repressor was able to gain access to the mammalian chromosome to regulate a stably integrated reporter gene.

Our goal has been to adapt the lac regulatory system to control gene expression in the mouse. In an earlier paper, we reported that transgenes containing the bacterial-coding sequence for the lac repressor downstream of the $\beta$-actin promoter were heavily methylated and only transcribed in the testis of transgenic mice (Scrable and Stambrook 1997). Methylation and silencing in mice also was observed by Wyborski et al. when the bacterial lac repressor sequence was downstream of the F9-1 polyoma promoter (Wyborski et al. 1996). To create an active transgene, we changed the primary DNA sequence of the bacterial lacI gene to resemble a mammalian coding sequence more closely and still code for the same aminoacid sequence. This synlacI gene was transcribed widely (Scrable and Stambrook 1997). However, we could not detect the synlacI protein product, either by Western blot or immunocytochemically, in the tissues of SynlacI transgenic mice or in cells transfected with the synlacI transgene. We also could not detect any effect of the repressor from synlacI on reporter-gene activity, either in embryonic mouse cells from transgenic animals, or in melanoma, neuronal, or kidney cell lines transfected with the synlacI transgene (data not shown).

In this paper, we describe how we changed the DNA sequence and gene structure of lacI so that it expresses functional lac repressor protein ubiquitously in mice. We show that the lac repressor can repress the activity of a reporter gene, which subsequently can be derepressed by IPTG in the drinking water of an adult or the mother of an embryo or nursing pup. The lac operator-repressor 
system brings the temporal dimension of mammalian gene expression in the animal under experimental control that is both reliable and predictable, and should make it possible to introduce even lethal mutations into the mouse genome routinely and to study them at the organismal level.

\section{Results}

Reversion of four bases to the wtlacI sequence corrects a cryptic splice site in synlacI

To determine why no protein was observed from the synlacI transgenes, we analyzed the RNA transcripts for evidence of processing errors. We consistently observed a single transcript on Northern blots of RNA from animals transgenic for the bacterial, or wtlacI (W) construct, but a doublet in RNA from animals with the re-encoded, or synlacI (S) transgene (Scrable and Stambrook 1997; Fig. 3 , below). The sizes of the two transcripts with synlacI suggested that the upper band represented an unspliced transcript still containing an intron from the human $\beta$-actin promoter, and the lower band, the spliced transcript. On careful examination of synlacI and wtlacI transcripts, we found that the processed synlacI transcript was actually slightly smaller than the wtlacI transcript. Incorrect splicing at a cryptic splice acceptor site downstream of the start codon could explain both the smaller size of the RNA and the absence of protein product. We developed an RT-PCR assay, with primers that flank the region encompassing the intron in the $\beta$-actin promoter and the translation start site in the lac repressor coding region (Fig. 1A, arrows). The difference in size between the correctly spliced $\mathrm{W}$ product and the correctly spliced S product (513bp vs. $499 \mathrm{bp}$ ) is due to a difference in the size of the region linking the promoter to the coding region (see Materials and Methods). As can be seen in Figure 2A, the predominant product in RNA from the $\mathrm{W}$ animal is the correctly spliced product, whereas the predominant product in the $S$ animal is smaller. This suggests that an aberrantly large region is spliced out of the synlacI transcripts.

We prepared a series of chimeric repressors made by exchanging the $5^{\prime}$ region of the wtlacI or synlacI constructs, as represented schematically in Figure $1 \mathrm{~A} / 5^{\prime} \mathrm{C} 1-$ $\left.5^{\prime} \mathrm{C} 4\right)$ and analyzed the splicing patterns of the constructs in transfected cells. Only one of these $\left(5^{\prime} \mathrm{C} 1\right)$ produced the correctly spliced product as the predominant PCR product (Fig. 2A). We correlated the splicing pattern with the presence of specific regions from $\mathrm{W}$ and $\mathrm{S}$, and we found that the first 36 bp of the synlacI coding sequence was the only region consistently associated with incorrect splicing. Within these first $36 \mathrm{bp}$ of coding sequence, the wtlacI and synlacI constructs differ by only four bases, as shown in Figure 2B.

Analysis of potential splice sites was performed using the Walkers sequence analysis program (Rogan et al. 1998). The only potential donor site in the transgenes is the splice donor site in the $\beta$-actin promoter. For the splice acceptor, in addition to the site in the $\beta$-actin pro-
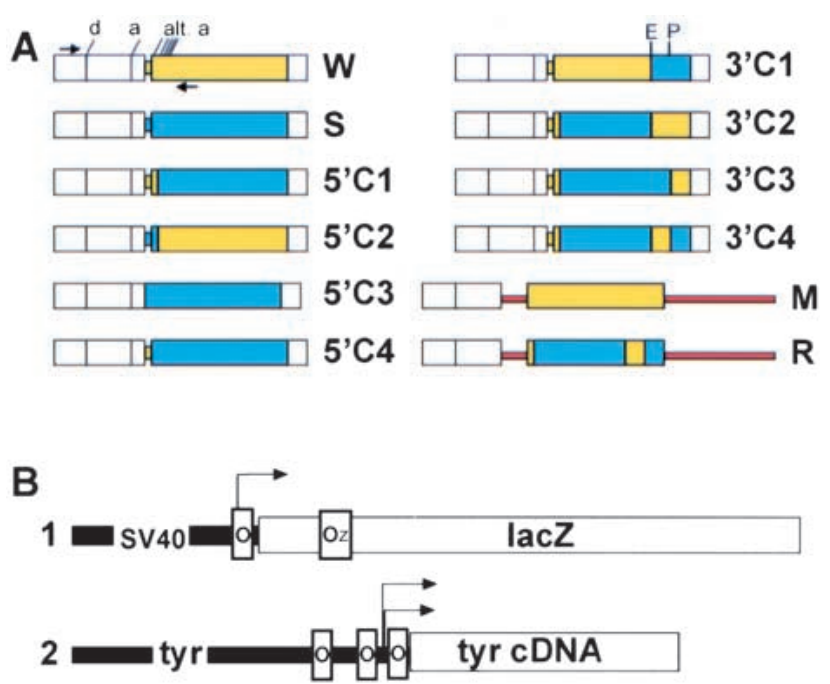

Figure 1. Schematic representation of lacI transgenes $(A)$ and target transgenes $(B)$. $(A)$ The lacI transgenes. All constructs are driven by a $4.3-\mathrm{kb}$ fragment of the human $\beta$-actin promoter (shown in white; only the $3^{\prime}$ region of the promoter is represented), containing an intron indicated by the splice donor (d) and acceptor (a) sites. For each construct, the coding region for the lac repressor is derived from segments of the wtlacI (W, shown in yellow) and synlacI ( $\mathrm{S}$, shown in blue) coding regions as indicated. The first four chimeras were made by exchanging the linker between the promoter and coding region, and/or the $5^{\prime}$ part of the coding region $\left(5^{\prime} \mathrm{C} 1-4\right)$ between $\mathrm{W}$ and $\mathrm{S}$. The next four chimeras were made by exchanging $3^{\prime}$ segments of the coding region $\left(3^{\prime} \mathrm{C} 1-4\right)$. In the last two constructs, $\mathrm{M}(\mathrm{W}$ coding region) and $\mathrm{R}$ ( $3^{\prime} \mathrm{C} 4$ coding region), the coding region is flanked by segments of the rabbit $\beta$-globin locus (shown in red). (alt. a, potential alternative splice acceptor sites present in the lacI coding region; E and P, EcoRV and PVuII restriction enzyme sites; arrows indicate position of primers used for the PCR shown in Fig. 2). (B) The lac operator containing target transgenes. (1) SVOZ. The SV40 early promoter containing a single, symmetric lac operator drives expression of the $\beta$-galactosidase (lacZ) reporter gene, which contains the endogenous $\mathrm{O}_{z}$ operator. (2) The regulatable Tyrosinase transgene (Tyr ${ }^{\mathrm{lacO}}$ ). Three lac operators have been introduced into the murine tyrosinase promoter. The primary operator was centered just downstream of the start of transcription by changing the endogenous promoter sequence; two additional operators were inserted $176 \mathrm{bp}$ and 526 $\mathrm{bp}$ upstream. The modified promoter drives expression of the $w t$ murine tyrosinase cDNA.

moter, there is a potential site just downstream of the four bases that differ between $\mathrm{W}$ and $\mathrm{S}$ in the lacI coding region (Fig. 2B). Based on the size of the smaller product identified by our RT-PCR assay, this potential site is the acceptor site utilized in synlacI. We cannot explain why this acceptor site is used rather than the splice-acceptor site in $\beta$-actin, which by current models should be stronger.

Reversion of a 3' region of the coding sequence to wtlacI corrects a translational block in synlacI

To test whether the constructs coded for functional lac repressor protein, we introduced each into Rat2 fibro- 
A

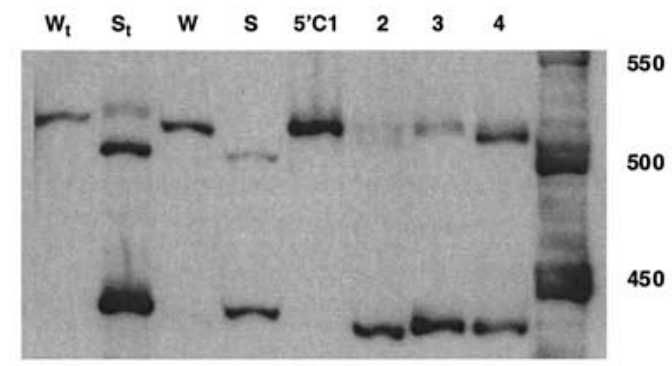

B
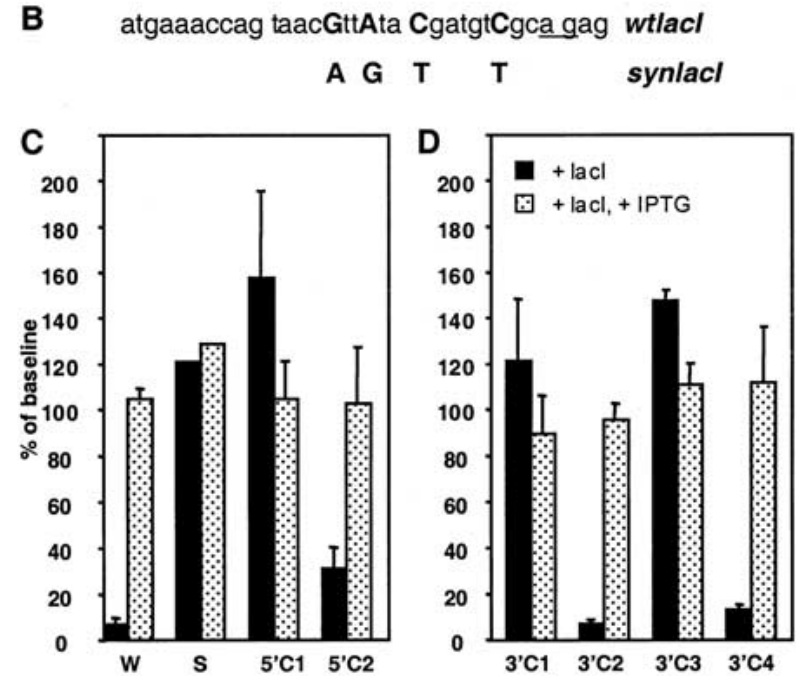

Figure 2. Modifications to the coding region alter splicing and function of the lac repressor transgenes. (A) Splice-site utilization. RT-PCR of spliced products transcribed from the different lac repressor constructs produced with the primers indicated in Figure 1. Lanes $W_{t}$ and $S_{t}$ contain products amplified from total RNA from testis of animals transgenic for the wtlacI and synlacI transgenes, respectively. All other products are from total RNA of Rat2 cells transfected with the indicated construct. The size of the correctly spliced product (utilizing both the splice donor and splice acceptor sites in the $\beta$-actin promoter) is $513 \mathrm{bp}$ for $\mathrm{W}$, $5^{\prime} \mathrm{C} 1$, and $5^{\prime} \mathrm{C} 4 ; 499$ bp for $\mathrm{S}$ and $5^{\prime} \mathrm{C} 2$; and 476 bp in $5^{\prime} \mathrm{C} 3$ (see Materials and Methods). Note that $5^{\prime} \mathrm{Cl}$, which contains the wtlacI sequence at the beginning of the coding region, is the only construct other than $\mathrm{W}$ to produce predominantly the correctly spliced product. $(B)$ Sequence differences in the region controlling splicing. Bases in the $5^{\prime}$ coding region that differ between wtlacI and synlacI are shown in bold uppercase. The underlined ag indicates the proposed (incorrectly utilized) splice acceptor site in the constructs containing the beginning of the coding region from synlacI. $(C, D)$ Repression of reporter-gene activity by different lac repressor transgenes. Graphs of $\beta$-galactosidase reporter-gene activity in Rat2 cells transfected with the regulatable SVOZ construct in combination with the lac repressor construct indicated. Data are expressed as a percentage of the baseline $\beta$-galactosidaseexpressing cells in the absence of lac repressor. $(C)$ Repressor activity of the parental transgenes (W and S) are shown along with repressor activity of $5^{\prime} \mathrm{C} 1$ and $5^{\prime} \mathrm{C} 2$. Note that $5^{\prime} \mathrm{C} 1$, which is the correctly spliced synlacI construct, does not produce functional repressor activity, indicating that correction of splicing does not restore repressor function. $(D)$ Repressor activity of the 3' chimeras. Note that those constructs with the wtlacI sequence between the EcoRV and PvuII sites $\left(3^{\prime} \mathrm{C} 2\right.$ and $\left.3^{\prime} \mathrm{C} 4\right)$ produce functional repressor, whereas those with the synlacI sequence in this region $\left(3^{\prime} \mathrm{C} 1\right.$ and $\left.3^{\prime} \mathrm{C} 3\right)$ do not. blasts by transient transfection along with the regulatable target gene, SVOZ (Fig. 1B). SVOZ consists of a modified SV40 early promoter with a single lac operator between TATA and the transcription start site (Brown et al. 1987), and the $\beta$-galactosidase (lacZ) reporter gene (which was shown to be regulatable with the lac repressor and IPTG in Liu et al. (1989). Reporter-gene activity was assessed under the following four conditions: (1) $S V O Z$ alone (the basal level of activity); (2) SVOZ + IPTG (the effect of IPTG on unrepressed activity); (3) SVOZ + lac repressor (repression); and (4) SVOZ + lac repressor + IPTG (derepression). In all experiments, there was no significant difference between conditions 1 and 2, indicating that IPTG alone had no effect on the unrepressed level of expression. The average of conditions 1 and 2 was taken as the baseline expression for each transfection. The numbers of blue cells under conditions 3 and 4 were expressed as percent of the unrepressed baseline.

The results for the constructs $\mathrm{W}, \mathrm{S}, 5^{\prime} \mathrm{C} 1$, and $5^{\prime} \mathrm{C} 2$, are shown in Figure 2C. As expected from our previous studies, $\mathrm{W}$ encodes a functional repressor whereas $\mathrm{S}$ does not. However, $5^{\prime} \mathrm{Cl}$, which was found to splice correctly, does not encode a functional repressor. And surprisingly, $5^{\prime} \mathrm{C} 2$, which gives predominantly an incorrectly spliced product like $\mathrm{S}$, does code for functional repressor, although the level of repression is not as tight as with $\mathrm{W}$ $(31 \%$ vs. $7 \%)$. These results indicated that, in addition to splicing, there was a second problem with the synlacI coding region that affected the expression of functional repressor.

We made a second set of chimeras in which $3^{\prime}$ regions of the $\mathrm{W}$ and $\mathrm{S}$ coding sequences were exchanged. These constructs are represented schematically in Figure 1A $\left(3^{\prime} \mathrm{C} 1-3^{\prime} \mathrm{C} 4\right)$. As represented graphically in Figure 2D, both $3^{\prime} \mathrm{C} 2$ and $3^{\prime} \mathrm{C} 4$ had repressor activity, whereas $3^{\prime} \mathrm{C} 1$ and $3^{\prime} \mathrm{C} 3$ did not. These data indicate that the problematic region in synlacI is in the 150 bp between the $5^{\prime}$ EcoRV site and the 3' PvuII site. Within this region, W and $\mathrm{S}$ differ by only 16 bases. We could find no coding error, cloning artifact, or other mutation in this region that could account for the lack of repressor function. We used site-directed mutagenesis to change all 16 bases in synlacI, in groups of two to five to the wtlacI sequence. None of these smaller changes could restore repressor function on their own (data not shown).

We hypothesized that loss of repressor function was the result of a synlacI sequence element located between the EcoRV and PvuII restriction sites that blocked RNA transcripts from being translated. This hypothesis is supported by our finding that a synlacI construct that splices correctly $\left(5^{\prime} \mathrm{C} 1\right)$ is expressed strongly at the RNA level, but is only barely detectable at the protein level (data not shown). Two mechanisms that could account for this translational block are: (1) nuclear retention of the RNA such that it does not reach the cytoplasm to be transcribed; or (2) tight secondary structure of the RNA such that the translation machinery cannot access the primary sequence. The first hypothesis was ruled out by finding that equal levels of lacI message were seen in the total and cytoplasmic fractions of both wtlacI and 
synlacI RNA extracts on Northern blot (data not shown). The second hypothesis was ruled out by analyzing the secondary structure predicted for each RNA sequence (Zuker et al. 1991) in which no significant differences were found (data not shown). Consequently, we can conclude that the expression of functional lac repressor activity is blocked by the region of the synlacI sequence between the EcoRV and PvuII sites, but the mechanism responsible for this block is not known.

\section{Restructuring optimizes transcription of CpG-rich lacI transgenes in the mouse}

Having identified a modified synlacI coding sequence that was correctly spliced and translated in transfected cells (3'C4), we derived transgenic mice with this construct. We analyzed lacI expression by Northern blot, and the results are shown in Figure 3. We found that 3'C4 transgenes were expressed only in testis, resembling transgenes composed entirely of bacterial coding sequence. (See Materials and Methods for details on the mouse lines for each transgene).

We knew from our previous studies that the content of CpG dinucleotides in the coding sequence was a major determinant of RNA expression in the animal (Scrable and Stambrook 1997). The bacterially derived W construct contains $97 \mathrm{CpG}$ dinucleotides in the coding re-

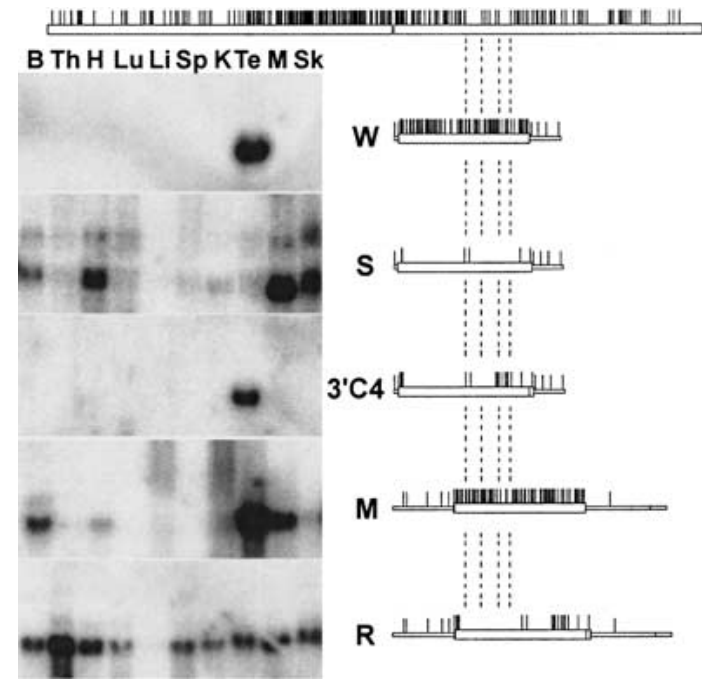

Figure 3. CpG content and gene structure influence transcription of lacI transgenes in the mouse. The lac repressor transgenes that have been used to derive transgenic mice are shown schematically on the right. Each line above the construct map indicates the position of a $\mathrm{CpG}$ dinucleotide. The $\mathrm{CpG}$ pattern of the endogenous human $\beta$-actin promoter and coding region are shown at the top for comparison. Northern blots of $30 \mu \mathrm{g}$ total RNA from tissues of a mouse transgenic for each of the constructs are shown on the left. The dashed lines highlight two CpG-poor regions in the $\beta$-actin locus and their corresponding locations in the lacI transgenes. (B, brain; Th, thymus; $\mathrm{H}$, heart; Lu, lung; Li, liver; Sp, spleen; K, kidney; Te, testis; M, muscle; Sk, skin). gion and $5^{\prime}$ linker and is expressed only in the testis of transgenic mice. Removal of all but five of these CpG dinucleotides resulted in the $S$ construct, which was expressed in all tissues (Scrable and Stambrook 1997). To examine the arrangement of $\mathrm{CpG}$ dinucleotides in each transgene more closely, we created CpG-density maps of each one and then aligned them with the CpG-density map of the $\beta$-actin locus (Fig. 3). In the endogenous $\beta$-actin locus there is a CpG island, which extends from the proximal promoter into the $\beta$-actin coding region. The high CpG content of $\mathrm{W}$ downstream of the $\beta$-actin promoter results in recapitulation of the $\mathrm{CpG}$ island in the $\beta$-actin locus, but both $\mathrm{S}$ and $3^{\prime} \mathrm{C} 4$ are relatively devoid of $\mathrm{CpG}$ in this same region. However, $\mathrm{S}$ is expressed like $\beta$-actin and $3^{\prime} \mathrm{C} 4$ is expressed like $\mathrm{W}$.

Next, we made two constructs in which either $\mathrm{W}$ or 3'C4 coding regions were flanked with noncoding regions derived from the rabbit $\beta$-globin gene (constructs $\mathrm{M}$ and $\mathrm{R}$, respectively). This added $\mathrm{CpG}$-poor sequences to the transgenes, and moved the respective lacI coding regions farther away from their promoters. As shown in Figure 3, the $M$ line does have a more widespread expression pattern than the $\mathrm{W}$ line, although it is not ubiquitous. However, the combination of the relatively $\mathrm{CpG}$ poor coding region of $3^{\prime} \mathrm{C} 4$ and the flanking globin sequences (R) results in global lacI transcription (Fig. 3).

One possible explanation for these different expression patterns is that an open structure that allows for transcriptional activity relies on a downstream element in the $\beta$-actin coding region that is free of CpG dinucleotides. There are several segments downstream of the promoter that are devoid of CpG. Two of these $\beta$-actin elements, and their analogous regions in each of the lacI constructs, are indicated by the dashed lines in Figure 3. In $\mathrm{W}$, both of these elements are $\mathrm{CpG}$-rich and transgene expression is restricted to testis. In $S$, the regions are CpG-poor, and expression is nearly ubiquitous. In 3'C4, replacement of the sequence between the EcoRV and PvuII sites in S with the corresponding sequence in $\mathrm{W}$ changed the distal element from one devoid of CpG to one that is CpG-rich, and the expression pattern from one that is ubiquitous to one restricted to the testis. Flanking the coding region of $3^{\prime} \mathrm{C} 4$ with the globin sequences shifted CpG-poor sequence into the two regions, and resulted in nearly ubiquitous expression, similar to the expression pattern of the endogenous $\beta$-actin gene.

\section{The lac repressor is widely expressed and functional in the LacI ${ }^{R}$ transgenic mice}

The key to using the lac repressor system in mice is expression of functional levels of repressor protein. We prepared tissue protein extracts and tissue sections from mice transgenic for the $\mathrm{R}$ transgene $\left(1 a c I^{R}\right)$ and analyzed the expression of the lac repressor by Western blot (Fig. 4A) and immunohistochemistry (Fig. 4B). There is no evidence of a translational block in any tissue tested (brain, thymus, heart, lung, liver, spleen, kidney, testis, muscle, and skin). The strong nuclear staining of the protein seen with immunohistochemistry is a result of a 
Cronin et al.

Figure 4. The lac repressor protein is widespread in the $\mathrm{LacI}^{\mathrm{R}}$ transgenic mouse. $(A)$ Western blot of total protein from $\mathrm{B}$, brain; $\mathrm{H}$, heart; Lu, lung; Li, liver; $\mathrm{S}$, spleen; $\mathrm{K}$, kidney; $\mathrm{T}$, testis; and $\mathrm{M}$, muscle of a $\mathrm{LacI}^{\mathrm{R}}$ transgenic mouse, ntT-testis of a nontransgenic mouse, reacted with a monoclonal antibody raised against the lac repressor. (B-F) Immunohistochemistry with a monoclonal antibody raised against the lac repressor on sections from $(B) \mathrm{LacI}^{\mathrm{R}}$ muscle; $(C) \mathrm{LacI}^{\mathrm{R}}$ skin; $(D)$ LacI $^{\mathrm{R}}$ hippocampus; $(E) \mathrm{LacI}^{\mathrm{R}}$ cerebellum; and $(F)$ nontransgenic cerebellum. Scale bar indicates $500 \mu \mathrm{m}$ in panels $B, E$, and $F ; 200 \mu \mathrm{m}$ in panels $C$ and $D$.
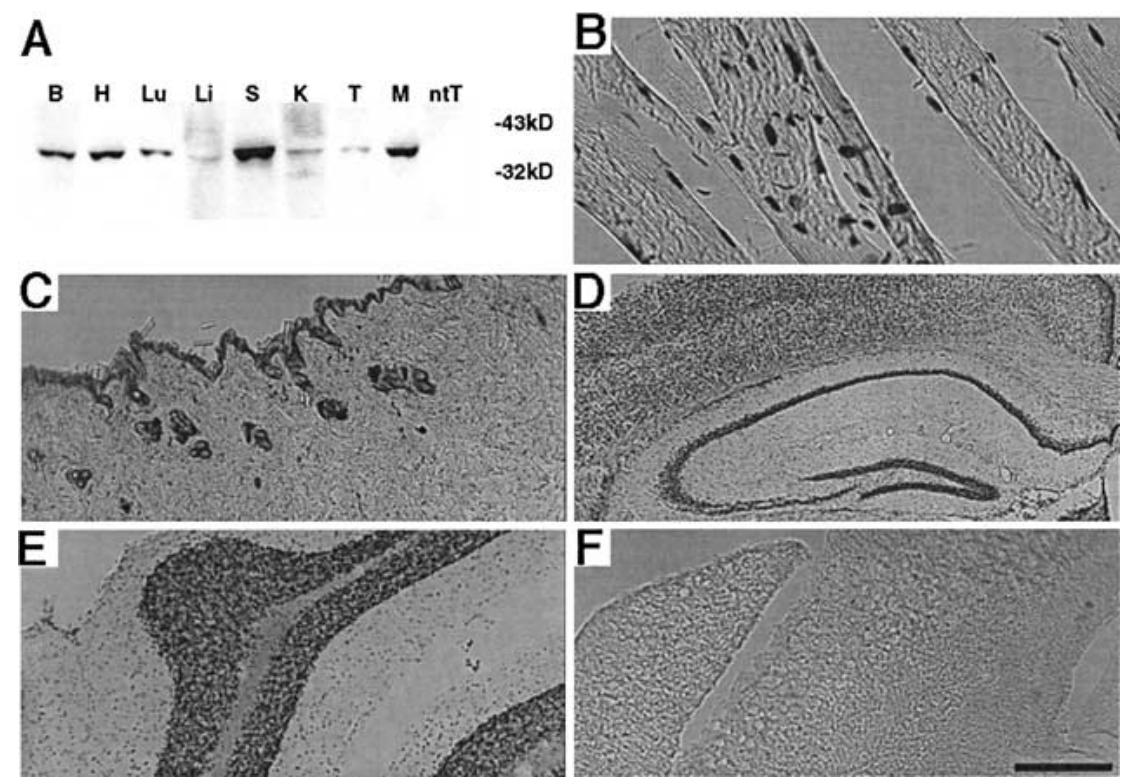

nuclear localization signal sequence appended to the carboxy terminal of the lac repressor (See Materials and Methods).

To determine if the lac repressor in this line is functional, we prepared cultures of primary embryonic cells from $\mathrm{R}$ animals and transfected them with the regulatable SVOZ construct. The embryo-derived cells exhibited strong lac repressor activity, as there was very little $\beta$-galactosidase expression in the absence of IPTG in the culture media (Fig. 5). A titration curve of the amount of IPTG needed to derepress expression shows that as little as $50 \mu \mathrm{M}$ IPTG in the culture media allows for full levels of expression (Fig. 5A), which correlates well with the level needed to derepress transcription at the bacterial lac operon (Cho et al. 1985). At $20 \mathrm{mM}$ IPTG in the media, we observed some toxicity, indicated by decreasing numbers of $\beta$-galactosidase-positive cells (Fig. 5B). Although the level at which toxicity was observed agrees well with the findings of Figge et al. (1988), we found that full derepression was achieved at a much lower concentration of IPTG.

\section{Target gene activity is controlled by $\mathrm{LacI}^{\mathrm{R}}$ and IPTG in the mouse}

We tested the lac operator-repressor system in mice using a regulatable version of a well-characterized visible marker gene, tyrosinase. Tyrosinase is the protein product of the albino (c) locus (Kwon et al. 1987), and is the enzyme that catalyzes the first step in melanin biosynthesis. The target transgene consists of the wildtype murine tyrosinase cDNA under the control of the murine tyrosinase promoter modified to contain lac operator sequences. The major transcription start site in the tyrosinase promoter is $83 \mathrm{bp}$ upstream of the start codon. To maintain the endogenous spacing of promoter elements in the critical region between the start of transcription and the start of translation, we used PCR-based, sitedirected mutagenesis to change $25 \mathrm{bp}$ of the endogenous sequence to create a primary lac operator centered at 59 bp upstream of the start of translation. Additional operators were inserted $176 \mathrm{bp}$ and $526 \mathrm{bp}$ upstream of the primary operator (Fig. 1B).

Mice containing this modified Tyrosinase transgene resemble pigmented animals previously described (Yokoyama et al. 1990; Methot et al. 1995) that had been microinjected with an unregulatable version of the same transgene. We established two lines of pigmented Tyrosinase transgenic mice with the regulatable transgene. The Tyr ${ }^{\text {lacO }}-25$ line displays a himalayan pigmentation pattern (as shown in Figs. 6A and 7C), and the Tyr ${ }^{\text {lacO }}-43$ displays a light pigmentation pattern, similar to those described in Methot et al. (1995).

We crossed mice transgenic for the Tyrosinase transgene to mice transgenic for $L a c I^{R}$. In double transgenics, the lac repressor should bind to the operator sequences located in the tyrosinase promoter, block transcription of tyrosinase, and revert pigmented animals to albino. An example of a Tyr ${ }^{\text {lacO }}-25$, LacI $^{\mathrm{R}}$ double-transgenic mouse is shown in Figure 6A next to a mouse transgenic for Tyr ${ }^{\text {lacO }}-25$ alone. The coat of the double transgenic is unpigmented and indistinguishable from that of a nontransgenic albino. Treatment of a double transgenic animal with $10 \mathrm{mM}$ IPTG in the drinking water derepressed tyrosinase expression, resulting in a phenotype indistinguishable from that of the mouse transgenic for

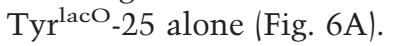

The stringency of repression and derepression is illustrated by the pigmentation of the eye. Figure $6 \mathrm{~B}$ shows dissected eyes, and Figure 6C shows sections through the eyes of a nontransgenic albino, a Tyr transgenic, a Tyr, $\mathrm{LacI}^{\mathrm{R}}$ double transgenic, and a Tyr, LacI ${ }^{\mathrm{R}}$ double transgenic mouse treated with IPTG. Repression of target transgene expression is accompanied by an absence of 

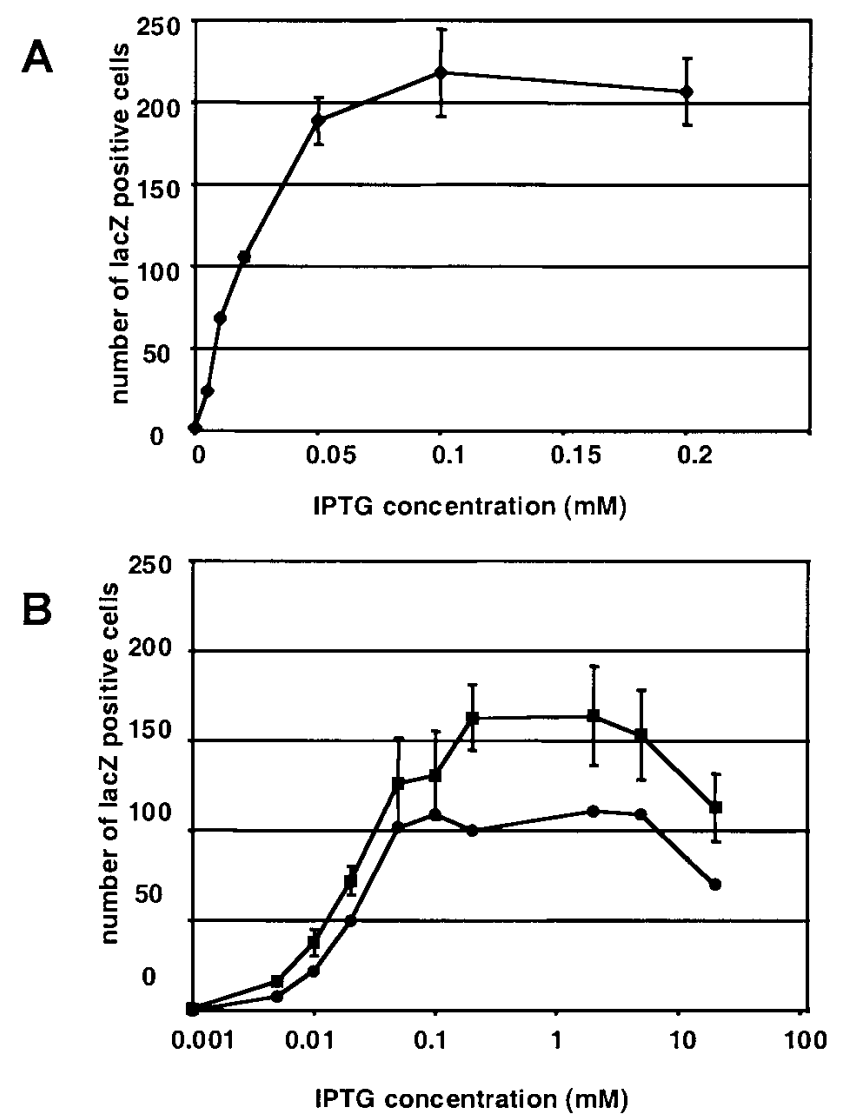

Figure 5. Low concentrations of IPTG derepress reporter gene activity in embryonic cells from $\mathrm{LacI}^{\mathrm{R}}$ transgenic mice. Embryonic cells were transfected with the SVOZ reporter gene and the number of $\beta$-galactosidase-positive cells assayed after growth in varying concentrations of the lactose analog IPTG. (A) Derepression response over the low range of IPTG in primary cells derived from an embryo from the R3 line transgenic for $\mathrm{LacI}^{\mathrm{R}}$. $(B)$ Derepression response on a logarithmic scale of IPTG concentrations for primary cells derived from an embryo from the R1 line transgenic for $\mathrm{LacI}^{\mathrm{R}}$ (circles), and a spontaneously immortalized cell line from the primary embryonic R3 cells (squares). Note that all cell lines reach maximal derepression at 0.05 to 0.1 mM IPTG. Both lines tested at higher concentrations $(B)$ showed a decrease in $\beta$-galactosidase-positive cells at $20 \mathrm{mM}$ IPTG, which may indicate a toxic level.

melanin in the retinal pigment epithelium (RPE) of the double-transgenic animal (Fig. 6C). The entire RPE is devoid of melanin, as can be seen by the completely unpigmented appearance of the eye in whole mount (Fig. 6B). Derepression by IPTG is accompanied by a restoration of pigmentation in the RPE to levels indistinguishable from the nonrepressed state (Fig. 6B,C). We obtained similar results with both lines of regulatable Tyrosinase mice (data not shown for Tyr ${ }^{\text {laco }}-43$ adults, but see Fig. 7). This indicates that regulation is neither insertion site specific nor simply fortuitous, but controlled by the lac repressor acting specifically on a target gene with lac operator sequences in its promoter. The albino mutation is a single basepair change in the coding sequence of tyrosinase, which causes a single amino acid change in the protein. Because the mutant allele is both transcribed and translated, we have not been able to assay promoter activity quantitatively at the molecular level. Nevertheless, we can infer from its effect on pigmentation that the tyrosinase promoter is in fact regulated by the lac operator-repressor system tightly, in a biologically relevant manner.

These results also show that IPTG can be introduced into the drinking water and circulate in the mouse at a level sufficient to derepress target gene expression. This level appears to be completely nontoxic. At the time of this writing, we have had $\mathrm{Tyr}^{\text {lacO }}, \mathrm{LacI}^{\mathrm{R}}$ double-transgenic mice on $10 \mathrm{mM}$ IPTG in their drinking water for up to 8 months with no deleterious effects.

\section{Regulation is functional during embryogenesis, and reversible}

We next wished to determine if lac elements could regulate pigmentation during embryogenesis and if IPTG could act transplacentally. Figure 7A and B shows the embryonic and newborn pigmentation of the $\mathrm{Tyr}^{\mathrm{lacO}}-43$ line. At E9, tyrosinase activity in the embryonic eye begins to deposit pigment in the developing retinal pigment epithelium. At E12.5, the mouse RPE clearly is pigmented (Drager 1985). As shown in Figure 7A, $\mathrm{Tyr}^{\text {lacO }}-43$ transgenic mice recapitulate this developmental event. A distinct band of pigmentation surrounding the central lens is seen in the Tyrosinase transgenic embryo that is not seen in the nontransgenic albino (Fig. 7A). The lac repressor blocked pigmentation during embryogenesis in the double-transgenic embryo, but not when the mother was treated with IPTG during pregnancy (Fig. 7A). These results clearly demonstrate not only that lac regulatory sequences function well during embryogenesis, but also that IPTG can cross the placenta to alter the phenotype of developing animals.

Finally, we tested the reversibility of the system by switching the Tyrosinase transgene on after it had been off, or off after it had been on, in the same animal. In Figure $7 \mathrm{~B}$, the phenotypes of eyes of newborn mice are compared to the phenotypes of embryonic eyes of mice of the same genotype. The mother of the IPTG-treated $\mathrm{Tyr}^{\mathrm{lacO}}, \mathrm{LacI}^{\mathrm{R}}$ double transgenic shown in Figure $7 \mathrm{~B}$ was not started on IPTG in her drinking water until E12.5 of the pregnancy. As is shown in Figure 7A, this doubletransgenic pup would have shown the albino phenotype at E12.5. The fully pigmented eyes seen at birth in this animal demonstrate that even after a period of silencing, derepression by IPTG was able to switch tyrosinase expression on. Figure 7C illustrates that reversibility is also possible in the opposite direction. The Tyr ${ }^{\mathrm{lacO}}-25$, $\mathrm{LacI}^{\mathrm{R}}$ double-transgenic pup shown on the left at P8 was taken off IPTG at P9. Removal of IPTG caused reversion of the phenotype to albino, as shown in the picture of the same animal as an adult on the right. As expected, the eyes remain pigmented due to the low turnover of cells and melanosomes in the RPE. 
Cronin et al.

Figure 6. IPTG controls $\mathrm{Lacl}^{\mathrm{R}}$ repression of the $\mathrm{Tyr}^{\mathrm{lacO}}$ target gene in the mouse. Mice $(A)$, dissected eyes $(B)$, and cross-sections through eyes $(C)$. Note that the nontransgenic albino and the $\mathrm{Tyr}^{\mathrm{lacO}}, \mathrm{LacI}^{\mathrm{R}}$ double transgenic lack pigmentation, whereas the Tyrosinase transgenic and the $\mathrm{Tyr}^{\mathrm{lacO}}$, $\mathrm{LacI}^{\mathrm{R}}$ double transgenic that has been treated with IPTG are pigmented. (ONL, outer nuclear layer; RPE, retinal pigment epithelium; Scale bar represents $25 \mu \mathrm{m}$ in C).
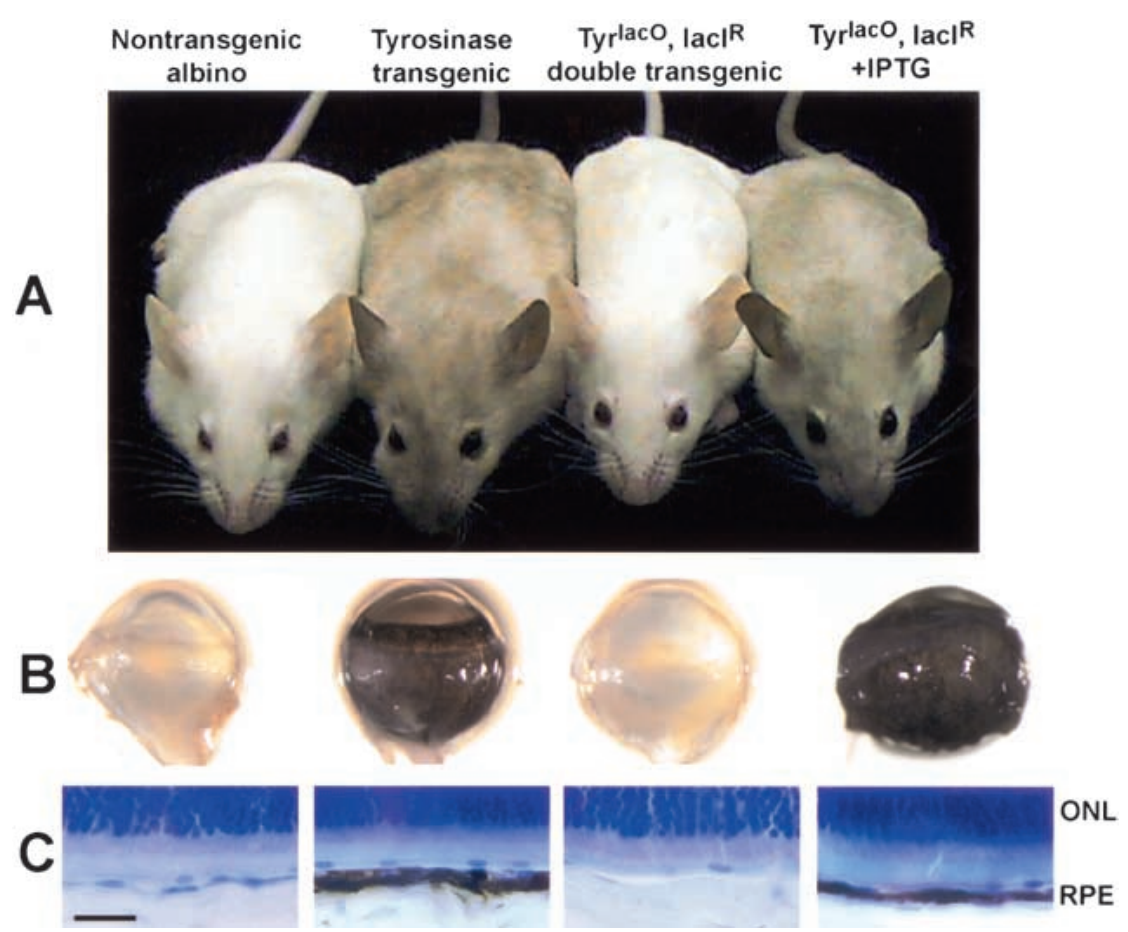

regulatory systems used in mice. This system is a technological advance that should increase significantly the kinds of experimental questions that can be addressed in a mammalian model system.

A re-encoded, restructured version of the bacterial lacI gene can transit embryogenesis without being silenced and can function like a normal mammalian gene

Experiments using the lac operator-repressor system in cultured mammalian cells (Brown et al. 1987;
Figure 7. Control of the $\mathrm{Tyr}^{\mathrm{lacO}}$ target gene is reversible during embryogenesis and after birth. (A) Photomicrographs of embryonic eyes at E12.5. As shown in the far right panel, IPTG can cross the placenta and induce pigmentation in the $\mathrm{Tyr}^{\mathrm{lacO}}$, $\mathrm{LacI}^{\mathrm{R}}$ double transgenic RPE, just as in the adult shown in Figure 6. (EC, eye-cup edge; $\mathrm{RPE}$, retinal pigment epithelium; L, lens). (B) Photographs of P3 mice. The corresponding appearance of the eyes at birth is shown for each genotype. The mother of the double-transgenic animal shown in the panel on the far right was started on IPTG at E12.5. The eye pigmentation seen at birth shows that even after the transgene has been silenced by the lac repressor (as demonstrated by the albino phenotype of the Tyr ${ }^{\text {lacO }}$, LacI ${ }^{\mathrm{R}}$ double-transgenic E12.5 eye in panel $A$ ), it can be derepressed by IPTG. $(C)$ Tyrosinase can be silenced after a period of derepression. Left and right panels show the same Tyr ${ }^{\text {lacO }}, \mathrm{LacI}^{\mathrm{R}}$ double transgenic animal. On the left as an infant (P8) and on the right as an adult. IPTG was discontinued at $\mathrm{P} 9$, causing reversion to an albino phenotype in the adult.

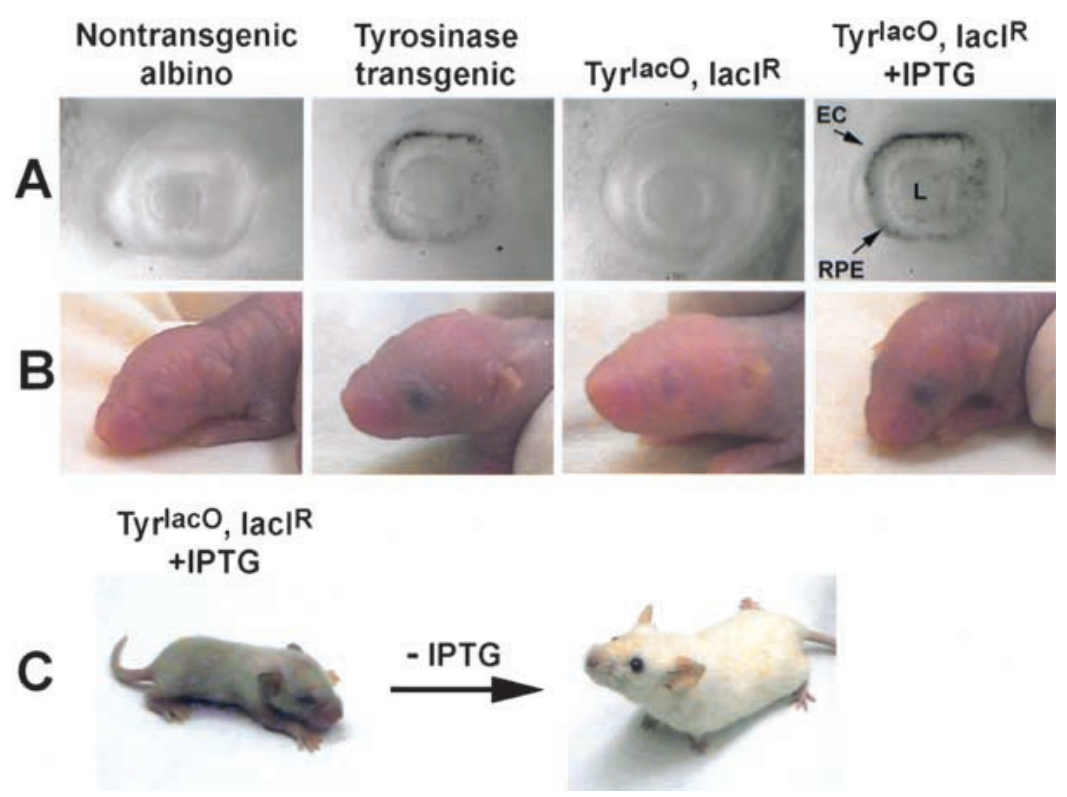


Hu and Davidson 1987; Figge et al. 1988; Liu et al. 1989) suggested that bacterial sequences could be processed into proteins and function in the compartmentalized eukaryotic cell as effectively as they had in the simpler prokaryotic cell. In contrast to results in cultured cells, bacterial sequences in animals were expressed sporadically (Scrable and Stambrook 1997) or with the assistance of toxic chemicals such as the demethylating agent 5-azacytosine (Wyborski et al. 1996).

To use the lac repressor in animals, bacterial and viral elements had to be changed into their mammalian counterparts, or eliminated entirely. The most time-consuming challenge was to adapt the lacI coding sequence so that it would go through sexual reproduction and embryogenesis without losing the ability to be transcribed. Embryogenesis is the great dividing line between cultured cells and animals. Genome-wide changes occur during gametogenesis, at cleavage, and at implantation, when epigenetic modifications such as methylation completely alter the chromatin environment of individual genes. The discovery that transgenes are imprinted with gamete-of-origin-specific methylation patterns similar to those laid down on endogenous genes (Swain et al. 1987) highlights the fact that artificially introduced sequences also must contain the requisite signals that will allow them to reemerge from embryogenesis functionally intact.

We think that a large part of the failure to produce mice expressing functional lac repressor prior to now can be attributed to a still incomplete understanding of what all of those signals are. We had to determine empirically those sequences that changed the splicing pattern of the RNA in a manner not predicted by sequence analysis. We identified a region of the synlacI sequence that for unknown reasons causes a block between transcription and translation. We identified structural elements that are critical for reliable transgene expression in the mouse, but whose mechanisms remain largely unknown. Thus, although it is possible to remodel a bacterial gene so that it will be expressed reliably in the context of a mammalian genome, our work with lacI demonstrates the difficulty of the task given the current state of knowledge of the molecular underpinnings of mammalian gene structure.

Insertion of lac operators into a mammalian promoter make it directly regulatable by the lac repressor

The target for the lac repressor is its DNA binding sequence, the lac operator. The lac operator is a short $1 \sim 25$ bp) sequence that easily can be incorporated into an existing promoter without compromising the efficacy of the promoter itself. In principle, this makes it possible to confer regulatability on virtually any mammalian gene simply by inserting operator sequences at appropriate sites in its promoter region. Our target promoter was a genomic fragment of DNA shown to be the promoter of the murine Tyrosinase gene (Kwon et al. 1987). It was modified at three sites, inserting a little more than 100 bp over $2.2 \mathrm{~kb}$ stretch of DNA, with lac operators posi- tioned in a way that simulated the overall structure of the regulatable promoter in the lac operon. The pigmentation patterns of our two founder lines both closely resembled the patterns of pigmentation observed in animals that had been microinjected with the unmodified Tyrosinase transgene (Yokoyama et al. 1990; Methot et al. 1995). These results indicate that the modifications we made to the promoter when we inserted lac operators did not have a significant, nonspecific impact on promoter activity. Tyrosinase activity originating at the transgene locus, as determined physiologically by the deposition of melanin, followed a normal pattern during development in the absence of repressor, further supporting our contention that operator insertion only minimally affected unrepressed promoter activity, if at all.

The lac operator-repressor system can reliably and predictably control the phenotype of the mouse

Reversible regulation of pigmentation in the transgenic mouse by elements from the lac operon of E. coli is the first successful demonstration that bacterial sequences can be used to create trans-operons in mice that function analogously to their bacterial counterparts. The normal or "ground" state of the regulated promoter is repressed, or inactive. In the case of our Tyr ${ }^{\mathrm{lacO}}$, $\mathrm{LacI}^{\mathrm{R}}$ double-transgenic mice, this results in a total lack of pigment and a phenotype indistinguishable from that of a nontransgenic albino. IPTG derepresses the regulated gene: tyrosinase is switched on and the phenotype of the derepressed transgenic animal becomes indistinguishable from that of the nonrepressed transgenic animal.

This all-or-none switch is achieved at a nontoxic dose of IPTG. We have seen full derepression in cells from the $\mathrm{LacI}^{\mathrm{R}}$ transgenic animals with as little as $50 \mu \mathrm{M}$ IPTG, which agrees with the levels needed in E. coli for derepression of the endogenous lac operon (Cho et al. 1985). This is in contrast to a previous result suggesting that the levels of IPTG needed for full expression with the lac system are toxic (Figge et al. 1988).

The lac operator-repressor system has advantages over the currently available gene regulatory systems for the mouse

To overcome the problems of embryonic lethality and developmental compensation that hinder the utility of traditional knockout strategies, a system was developed that allows target genes to be excised from the genome in a tissue-specific and timing-controlled manner. The Cre/ $\operatorname{lox} P$ recombination system (Gu et al. 1993, 1994) is based on the cre recombinase of bacteriophage P1 that catalyzes site-specific recombination between $l_{0 x} P$ sites. An advantage of cre-mediated excision is that the experimental manipulation can be performed on an endogenous locus. However, excision is a one-time event, which cannot be reversed. The lac system is fully reversible. In addition, by incorporating lac operators into a mammalian promoter by homologous recombination, it should be possible to regulate the expression of endog- 
enous loci, as has already been done at the CDC2 locus in cultured cells (Itzhaki et al. 1997). Thus, with the lac system, it should be possible to create reversible mouse models of disease and elucidate gene function in their natural context.

Reversible systems that use mammalian regulatory elements to control gene expression in cells and animals (such as heavy metal or hormone responsive systems) have been used for some time. They suffer from the fact that, by definition, the inducing agent also will have effects on endogenous genes. Regulatory systems based on elements from the bacterial tet and lac operons, on the other hand, are exquisitely specific for the gene of interest in the context of the mammalian genome.

To use the tet system of gene regulation in mammalian cells, Gossen and Bujard converted the tet repressor into the tet transactivator. This fusion of the tet repressor and the activating domain of the herpes simplex virus VP16 transcriptional activator, made it necessary to couple the tet operator to a viral promoter permanently (Gossen and Bujard 1992). Binding of repressor to operator serves to align the VP16 fusion partner with its specific binding site in the viral promoter, and it is the binding of VP16 to the viral promoter that activates transcription. The tet transactivator (tTA) or reverse transactivator (rtTA) no longer functions as a repressor, and instead functions analogously to the typical mammalian transcription factor. Tissue-specific gene expression can be achieved by having a specific mammalian promoter drive expression of the tet transactivator (or rtTA).

The ground state of the minimal viral promoter is one that is less active than the induced state, and binding of the transcription factor increases the activity of a promoter that is already in the active configuration. This has made the tet system particularly suited for those applications in the mouse in which the phenotype to be controlled depends on the relative levels of an active transgene. For example, hyperplasia (Guo et al. 1999; Xie et al. 1999), prion disease (Tremblay et al. 1998), cardiomyopathy (Redfern et al. 1999), and Huntington's disease (Yamamoto et al. 2000) all have been successfully modeled in mice using the tet-responsive minimal CMV promoter and the tTA or rtTA. The tet system also has been used to study the molecular mechanisms of memory formation (Mayford et al. 1996; Mansuy et al. 1998a,b) and the role of FGF7 in lung development and injury repair in the adult mouse (Tichelaar et al. 2000).

The drawbacks of using an activator-responsive promoter, however, become apparent in situations where it is desirable to switch the promoter between an inactive state and an active state that results in physiological levels of tissue-specific expression. The endogenous endothelin receptor-B locus was replaced with tet-regulated elements to determine the role of the receptor during embryogenesis (Shin et al. 1999). In addition to the enormous effort such an undertaking must have required, the use of the tet system to control gene expression in this way was not entirely predictable and induction was incomplete.
Tet relies on viral promoter elements, and in the mouse, nonmammalian promoters very frequently lead to erratic expression of downstream coding sequences (Furth et al. 1991). Low-level leakiness (Shockett et al. 1995) and heterogeneous expression (Redfern et al. 1999) have been problems with use of the minimal CMV promoter, and the VP16 activating domain has been found to be toxic to cells (Baron et al. 1997). Our approach of directly targeting the lac repressor to operator sequences incorporated into mammalian promoters completely eliminates the necessity of using viral promoters or viral DNA-binding proteins in conjunction with a prokaryotic-based regulatory system. A target gene made up entirely of mammalian elements is more likely both to maintain functionality after transiting embryogenesis and to be expressed in the appropriate tissue at the appropriate level. This lends the system a particularly strong element of predictability that other prokaryoticbased systems cannot match.

In summary, by modifying both the target promoter and the gene encoding the lac repressor, we have been able to adapt a regulatory system used in bacteria to control the transcription of genes so that it can function analogously in the complex environment of the mouse. The $\mathrm{LacI}^{\mathrm{R}}$ mouse described in this report expresses the lac repressor ubiquitously, so it can be used in the future to regulate other promoters with the same degree of control we have demonstrated for our regulatable Tyrosinase transgene. Targeting endogenous promoters should move the system to the next level, where endogenous loci can be switched on and off repeatedly to create reversible models of human disease and normal development in the mouse.

\section{Materials and methods}

\section{Construction of lac repressor genes}

The lac repressor constructs $\mathrm{W}, \mathrm{S}, 5^{\prime} \mathrm{C} 1,5^{\prime} \mathrm{C} 2,5^{\prime} \mathrm{C} 4,3^{\prime} \mathrm{C} 1,3^{\prime} \mathrm{C} 2$, $3^{\prime} \mathrm{C} 3$, and $3^{\prime} \mathrm{C} 4$ are driven by a $4.3-\mathrm{kb}$ promoter region from the human $\beta$-actin gene up to the AluI site at -7 (Leavitt et al. 1984). Followed by a short linker of either 44 bp (gatcagtcga cctgcagccc aagcttgata tcgaattcgg atct) in $\mathrm{W}, 5^{\prime} \mathrm{C} 1,5^{\prime} \mathrm{C} 4,3^{\prime} \mathrm{C} 1,3^{\prime} \mathrm{C} 2,3^{\prime} \mathrm{C} 3$, and $3^{\prime} \mathrm{C} 4$, or $30 \mathrm{bp}$ (gatcagtcga cetgcagcce aagcttcacc) in $\mathrm{S}$ and $5^{\prime} \mathrm{C} 2.5^{\prime} \mathrm{C} 3$ contains the $4.3-\mathrm{kb}$ promoter up to the start of translation with no polylinker. All of the above constructs contain the polyadenylation signal sequence from the bovine growth hormone gene (Woychik et al. 1982) connected to the $3^{\prime}$ end of the construct by a BamHI and EcoRI linker region (taggatcccc gggctgcagg aattc).

Coding regions for the original wtlacI (W) and synlacI (S) constructs are as previously described (Scrable and Stambrook 1997). 5' C1 and 5'C2 were made by switching the linker region and the first $36 \mathrm{bp}$ of the coding region between wtlacI and synlacI using the BsrFI site shared by both constructs. 5'C1 contains the wtlacI linker and first 36 bp of the coding region, and then the synlacI coding region. The nuclear localization signal sequence (NLS) that had been attached to the synlacI coding sequence was removed by PCR mutagenesis, so that $5^{\prime} \mathrm{C} 1$ codes for a protein identical in amino-acid sequence to the endogenous lac repressor. 5' $\mathrm{C} 2$ contains the synlacI linker and first $36 \mathrm{bp}$ of the coding region, and then the $3^{\prime}$ wtlacI coding 
region through the stop site. $5^{\prime} \mathrm{C} 3$ is identical to the endogenous $\beta$-actin promoter up to the ATG start site, then contains the original synlacI coding region. This was created by PCR mutagenesis to remove the linker region present in $\mathrm{S}$ and replace the $6 \mathrm{bp}$ missing between the AluI site and $+1.5^{\prime} \mathrm{C} 4$ contains the linker region from $\mathrm{W}$ and the entire synlacI coding region, with no NLS. This was created by PCR mutagenesis of $5^{\prime} \mathrm{C} 1$ to return the four bases in the beginning of the coding region that differ between $\mathrm{W}$ and S back to the synlacI sequence (see Fig. 2B). $3^{\prime} \mathrm{C} 1$ contains the wtlacI sequence from the start of translation up to the EcoRV site at +800 (which $\mathrm{W}$ and $\mathrm{S}$ have in common) and the synlacI sequence after the EcoRV site. The SV40 NLS is attached to the $3^{\prime}$ end of the $3^{\prime} \mathrm{C} 1$ coding region with the linker region (agcagcctgaggcct), as described (Fieck et al. 1992), and was created by PCR mutagenesis of the existing NLS linker region described in Scrable and Stambrook (1997). 3'C2 is identical to $5^{\prime} \mathrm{C} 1$ up to the EcoRV site, then identical to W downstream. $3^{\prime} \mathrm{C} 3$ is identical to $5^{\prime} \mathrm{C} 1$ up to the PvuII site at +950 from the start of translation, then identical to $\mathrm{W}$ downstream. $3^{\prime} \mathrm{C} 4$ is identical to $\mathrm{W}$ upstream of the PvuII site, then identical to $3^{\prime} \mathrm{C} 1$ downstream.

Constructs $\mathrm{M}$ and $\mathrm{R}$ contain the human $\beta$-actin promoter blunted at the $A s c I$ site at -70 followed by the rabbit $\beta$-globin intron 2 from the blunted NcoI site through the EcoRI site in exon 3. The lacI coding region is inserted at the EcoRI site. The $\mathrm{M}$ coding region is identical to $\mathrm{W}$, and the $\mathrm{R}$ coding region is identical to $3^{\prime} \mathrm{C} 4$. The rabbit $\beta$-globin fragment continues downstream of the lacI coding region to include the rest of exon 3 and intron 3 with a polyadenylation signal sequence. The polyA signal sequence from SV40 also is present at the $3^{\prime}$ end. All of the $\beta$-globin sequences and the SV40 polyA signal sequence are as described (Katsuki et al. 1988).

\section{RT-PCR assay for splice site use in lac repressor transcripts}

Total RNA was extracted from testis of $\mathrm{W}$ and $\mathrm{S}$ transgenic animals, or Rat 2 fibroblasts transfected by calcium phosphate with the indicated lacI construct using TRI Reagent (Molecular Research Products, Inc.). RNA was DNase treated with RQ1 DNase (Promega) and $1 \mu \mathrm{g}$ reverse transcribed with AMV-RT. cDNA was subjected to 30 rounds of amplification $\left(95^{\circ} \mathrm{C}\right.$ for 30 $\mathrm{sec}, 60^{\circ} \mathrm{C}$ for $30 \mathrm{sec}, 72^{\circ} \mathrm{C}$ for $1 \mathrm{~min}$.) using a primer in the $\beta$-actin promoter $\left(5^{\prime}\right.$ acagagcctcgcctttg $\left.3^{\prime}\right)$ and a primer in the lacI coding sequence $\left(5^{\prime}\right.$ tgcaggcagcttccaca $\left.3^{\prime}\right)$. PCR products were run on a $4 \%$ polyacrylamide gel in $1 \mathrm{X}$ TBE and transferred to Hybond -N+ membrane (Amersham) by semi-dry electrophoresis in NAQ transfer solution $(0.08 \mathrm{M}$ Tris- $\mathrm{HCl}, 0.118 \mathrm{M}$ Borate, $2.4 \mathrm{mM}$ EDTA, pH8.3) at $220 \mathrm{~mA}$ for $1 \mathrm{~h}$. The resultant Southern blot was UV crosslinked and then prehybridized and hybridized according to the methods described in Scrable and Stambrook (1997).

\section{Rat2 transfection assay for lac repressor function}

Rat 2 fibroblasts were transfected with $2.5 \mu \mathrm{g}$ pSVOZ DNA and $2.5 \mu \mathrm{g}$ of the indicated lac repressor construct DNA (or pBSSK carrier DNA) per $3 \times 10^{5}$ cells by standard calcium phosphatemediated transfection. Growth media was DMEM, 0.1 units/ $\mathrm{mL}$ penicillin/ $0.1 \mu \mathrm{g} / \mathrm{mL}$ streptomycin (Life Technologies), 5\% FCS (Hyclone); (with $20 \mathrm{mM}$ IPTG, if indicated). Two days after transfection, cells were fixed in $0.5 \%$ gluteraldehyde, incubated with X-gal containing solution $10.5 \mathrm{mg} \mathrm{X}$-gal in dimethylformamide, $44 \mathrm{mM}$ HEPES, $3 \mathrm{mM}$ potassium ferrocyanide, $3 \mathrm{mM}$ potassium ferricyanide, $1.5 \mathrm{mM} \mathrm{NaCl}, 0.13 \mathrm{mM} \mathrm{MgCl}_{2}$ at $\mathrm{pH}>$ 7) at $37^{\circ} \mathrm{C}$ overnight, and the number of blue cells in each well recorded. Data shown in Figure 2C and D represent the average of three or four transfections for each construct (except $\mathrm{S}$, which was only tested once in this Rat 2 assay, although similar results were obtained with over 10 transfections into other cell types).

\section{Nucleic acid extraction and blotting}

Northern blots were prepared as described in Scrable and Stambrook (1997), except that RNA was transferred to Biodyne A nylon membrane (Pall). DNA was extracted from tail biopsies using the simplified method as described in Laird et al. 1991. Southern blots were prepared and analyzed according to the methods given in Scrable and Stambrook (1997).

\section{Detection of lac repressor protein by Western blot and immunohistochemistry}

A panel of monoclonal antibodies to the lac repressor was created by injecting a LacI-TrpE fusion protein into mice. For Western blots, total protein was extracted into lysis solution $150 \mathrm{mM}$ Tris at $\mathrm{pH} 7.5,0.15 \mathrm{M} \mathrm{NaCl}, 1 \%$ Nonidet $\mathrm{P} 40)$, containing protease inhibitors $10.25 \%$ sodium deoxycholate, $1 \mathrm{mM} \mathrm{PMSF}, 2$ mM EGTA, $1 \mu \mathrm{M}$ leupeptin, $0.2 \mu \mathrm{M}$ aprotinin, $0.8 \mathrm{mM}$ N-ethylmalemide, $2 \mu \mathrm{M}$ pepstatin A). Protein concentration was determined by Lowry's assay, and $30 \mu \mathrm{g}$ run on a $12 \%$ SDS-PAGE gel. The proteins were transferred to nitrocellulose membrane with semi-dry electrophoresis, and blocked in 5\% dried milk in PBS overnight. The blot was incubated with biotinylated antilacI antibody $5 \mathrm{~F} 8(25 \mu \mathrm{g} / \mathrm{mL}$ in $1 \% \mathrm{BSA} / \mathrm{TBST})$ for $1 \mathrm{~h}$ at $37^{\circ} \mathrm{C}$, labeled with peroxidase (ABC reagent, Vector) and visualized with chemiluminscence (SuperSignal, Pierce) on a ChemiImager (Alpha Innotech Corp.).

For immunohistochemistry, mice were given a lethal dose of Nembutol sodium, and perfused with $4 \%$ paraformaldehyde for $30 \mathrm{~min}$. Tissues were placed in $20 \%$ sucrose overnight at $4^{\circ} \mathrm{C}$, frozen, sectioned at $30 \mu \mathrm{m}$, and thaw-mounted onto Superfrost Plus (Fisher) slides. Sections were incubated with biotinylaed anti-lacI antibody 9A5 $(3 \mu \mathrm{g} / \mathrm{mL}$ in $1 \%$ BSA $/ 0.3 \%$ Triton-X100 in PBS) overnight at $4^{\circ} \mathrm{C}$, labeled with peroxidase (ABC reagent, Vector), and visualized with DAB.

\section{Preparation of primary mouse embryo cells}

Pregnant females were euthanized on day E13.5 (where E0.5 was the day a vaginal plug was observed). The embryos were dissected out and a small section frozen for genotyping. Embryonic tissue was minced and placed in 2-mL dissociation solution [2 $\mathrm{mg} / \mathrm{mL}$ Collagenase B, $2 \mathrm{U} / \mathrm{mL}$ RQ1 DNase in RPMI 1640 media (GIBCO)] at $37^{\circ} \mathrm{C}$ for $2 \mathrm{~h}$, triturating the solution after $1 \mathrm{~h}$. Cells were spun at $175 \mathrm{~g}$, washed one time with Hank's BSS, plated with growth media [DMEM, 0.1 units/mL penicillin/0.1 $\mu \mathrm{g} / \mathrm{mL}$ streptomycin (GIBCO), 10\% FCS (Hyclone)], and transfected by calcium phosphate.

\section{Construction of the regulatable Tyrosinase transgene (Tyr ${ }^{\mathrm{lacO}}$ )}

The regulatable Tyr ${ }^{\text {laco }}$ transgene is based on the construct TYBS described in Yokoyama et al. (1990). The first lac operator was created by site-directed mutagenesis (ExSite, Stratagene). $25 \mathrm{bp}$ of the endogenous promoter sequence (from -72 to -48 ) was changed to make a 29 bp operator centered at -59 , identical in sequence to the primary operator of the lac operon (gtggaattgt gagcggataa caatttcac) (Lewis et al. 1996). Two additional operators with the same sequence were inserted as part of a $47 \mathrm{bp}$ fragment (agatct gtggaattgtgagcggataacaatttcac ggatccagatct) 
into the BsrGI site at -203 and the EcoRV site at -548 of the promoter.

\section{Production of transgenic mice}

Production of the $\mathrm{W}$ and S lines is described in Scrable and Stambrook (1997). The rest of the transgenic lines described were produced by microinjection into the outbred ICR line (Harlan) using standard procedures. We made two transgenic founders for the $3^{\prime} \mathrm{C} 4$ transgene; both showed the testis-only expression pattern shown in Figure 3. One founder line was established for the $\mathrm{M}$ construct. Three founders were transgenic for $\mathrm{R}$; two (lines 1 and 3 ) exhibited the ubiquitous expression shown in Figure 3, one (line 13) had more limited expression that ranged from low to moderate in various tissues. Eight founders were transgenic for $\mathrm{Tyr}^{\mathrm{lacO}}$; an $\mathrm{F} 1$ generation was produced from all eight, and two of those established pigmented transgenic lines (lines 25 and 43). Of the animals indicated as Tyrosinase transgenic, those in Figure 6A were homozygous for Tyraco, and all others were hemizygous for Tyr ${ }^{1 a c O}$. All lacI transgenic mice described were hemizygous for lacI.

\section{Analysis of eye pigmentation and IPTG treatment of mice}

For adult eyes, mice were given a lethal dose of Nembutol sodium, perfused transcardially $(1.25 \%$ paraformaldehyde, $1.5 \%$ gluteraldehyde, in $0.1 \mathrm{M}$ phosphate at $\mathrm{pH} 7.4$ ); eyes were dissected out and photographed. They then were embedded in parafin, sectioned at $10 \mu \mathrm{m}$, dewaxed in Xylene, hydrated in decreasing concentrations of ethanol, and reacted in cresyl violet $(0.5 \%$ in $20 \%$ ethanol, $\mathrm{pH}$ to 2.5 with glacial-acetic acid) for $8 \mathrm{~min}$, dehydrated, cleared, and mounted in DPX. For embryonic eyes, pregnant females were euthanized at E12.5, and the embryos removed. The head of each embryo was fixed in $2 \%$ paraformaldehyde in $0.1 \mathrm{M}$ phosphate $(\mathrm{pH} 7.4)$, and the lower half was taken for genotyping.

Tyrosinase activity was derepressed by replacing the drinking water with a $10 \mathrm{mM}$ solution of IPTG (changed every four days).

\section{Acknowledgments}

We are grateful to P. Stambrook for support during the early stages of the project; to M. Dalton, L. Abramova, and B. Bernier for assistance with mouse genotyping and excellent technical support; to M. Kimura and P. Overbeek for the plasmids $\mathrm{p} B s t N$ and pTYBS, respectively; to J. Ellis for assistance with splice site analysis; to E. Talley, G. Owens, I. McCaffrey, B. Maier, S. Medrano, and M. Burton for helpful comments. This work was supported by a grant from the National Center for Research Resources, NIH grant RR11102. C.A.C. was a recipient of an NRSA predoctoral fellowship, NIH grant MH12406.

The publication costs of this article were defrayed in part by payment of page charges. This article must therefore be hereby marked "advertisement" in accordance with 18 USC section 1734 solely to indicate this fact.

\section{References}

Baron, U., Gossen, M., and Bujard, H. 1997. Tetracycline-controlled transcription in eukaryotes: Novel transactivators with graded transactivation potential. Nucleic Acids Res. 25: 2723-2729.

Brown, M., Figge, J., Hansen, U., Wright, C., Jeang, K.T., Khoury, G., Livingston, D.M., and Roberts, T.M. 1987. lac repressor can regulate expression from a hybrid SV40 early promoter containing a lac operator in animal cells. Cell 49: 603-612.

Cho, S., Scharpf, S., Franko, M., and Vermeulen, C.W. 1985. Effect of iso-propyl-thio-beta-D-galactoside concentration on the level of lac-operon induction in steady state Escherichia coli. Biochem. Biophys. Res. Commun. 128: 12681273.

Drager, U.C. 1985. Birth dates of retinal ganglion cells giving rise to the crossed and uncrossed optic projections in the mouse. Proc. R. Soc. Lond. B. Biol. Sci. 224: 57-77.

Fieck, A., Wyborski, D.L., and Short, J.M. 1992. Modifications of the E. coli Lac repressor for expression in eukaryotic cells: Effects of nuclear signal sequences on protein activity and nuclear accumulation. Nucleic Acids Res. 20: 1785-1791.

Figge, J., Wright, C., Collins, C.J., Roberts, T.M., and Livingston, D.M. 1988. Stringent regulation of stably integrated chloramphenicol acetyl transferase genes by E. coli lac repressor in monkey cells. Cell 52: 713-722.

Furth, P.A., Hennighausen, L., Baker, C., Beatty, B., and Woychick, R. 1991. The variability in activity of the universally expressed human cytomegalovirus immediate early gene 1 enhancer/promoter in transgenic mice. Nucleic Acids Res. 19: 6205-6208.

Gossen, M. and Bujard, H. 1992. Tight control of gene expression in mammalian cells by tetracycline- responsive promoters. Proc. Nat1. Acad. Sci. 89: 5547-5551.

$\mathrm{Gu}, \mathrm{H} ., \mathrm{Zou}, \mathrm{Y} . \mathrm{R}$. , and Rajewsky, K. 1993. Independent control of immunoglobulin switch recombination at individual switch regions evidenced through Cre-loxP-mediated gene targeting. Cell 73: 1155-1164.

Gu, H., Marth, J.D., Orban, P.C., Mossmann, H., and Rajewsky, K. 1994. Deletion of a DNA polymerase beta gene segment in $\mathrm{T}$ cells using cell type-specific gene targeting. Science 265: 103-106.

Guo, Y., Zhao, J., Sawicki, J., Peralta Soler, A., and O'Brien, T.G. 1999. Conversion of $\mathrm{C} 57 \mathrm{Bl} / 6$ mice from a tumor promotionresistant to a - sensitive phenotype by enhanced ornithine decarboxylase expression. Mol. Carcinog. 26: 32-36.

$\mathrm{Hu}$, M.C. and Davidson, N. 1987. The inducible lac operatorrepressor system is functional in mammalian cells. Cell 48: $555-566$.

Itzhaki, J.E., Gilbert, C.S., and Porter, A.C. 1997. Construction by gene targeting in human cells of a "conditional" CDC2 mutant that rereplicates its DNA. Nat. Genet. 15: 258-265.

Jacob, F. and Monod, J. 1961. Genetic regulatory mechanisms in the synthesis of proteins. J. Mol. Biol. 3: 318-356.

Katsuki, M., Sato, M., Kimura, M., Yokoyama, M., Kobayashi, K., and Nomura, T. 1988. Conversion of normal behavior to shiverer by myelin basic protein antisense cDNA in transgenic mice. Science 241: 593-595.

Kwon, B.S., Haq, A.K., Pomerantz, S.H., and Halaban, R. 1987. Isolation and sequence of a cDNA clone for human tyrosinase that maps at the mouse c-albino locus. Proc. Natl. Acad. Sci. 84: 7473-7477.

Laird, P.W., Zijderveld, A., Linders, K., Rudnicki, M.A., Jaenisch, R., and Berns, A. 1991. Simplified mammalian DNA isolation procedure. Nucleic Acids Res. 19: 4293.

Leavitt, J., Gunning, P., Porreca, P., Ng, S. Y., Lin, C.S., and Kedes, L. 1984. Molecular cloning and characterization of mutant and wild-type human beta-actin genes. Mol. Cell Biol. 4: 1961-1969.

Lewis, M., Chang, G., Horton, N.C., Kercher, M.A., Pace, H.C., Schumacher, M.A., Brennan, R.G., and Lu, P. 1996. Crystal structure of the lactose operon repressor and its complexes with DNA and inducer. Science 271: 1247-1254.

Liu, H.S., Feliciano, E.S., and Stambrook, P.J. 1989. Cytochem- 
ical observation of regulated bacterial beta-galactosidase gene expression in mammalian cells. Proc. Natl. Acad. Sci. 86: $9951-9955$.

Mansuy, I.M., Mayford, M., Jacob, B., Kandel, E.R., and Bach, M.E. 1998a. Restricted and regulated overexpression reveals calcineurin as a key component in the transition from shortterm to long-term memory. Cell 92: 39-49.

Mansuy, I.M., Winder, D.G., Moallem, T.M., Osman, M., Mayford, M., Hawkins, R.D., and Kandel, E.R. 1998b. Inducible and reversible gene expression with the rtTA system for the study of memory. Neuron 21: 257-265.

Mayford, M., Bach, M.E., Huang, Y.Y., Wang, L., Hawkins, R.D., and Kandel, E.R. 1996. Control of memory formation through regulated expression of a CaMKII transgene. Science 274: $1678-1683$.

Methot, D., Reudelhuber, T.L., and Silversides, D.W. 1995. Evaluation of tyrosinase minigene co-injection as a marker for genetic manipulations in transgenic mice. Nucleic Acids Res. 23: 4551-4556.

Redfern, C.H., Coward, P., Degtyarev, M.Y., Lee, E.K., Kwa, A.T., Hennighausen, L., Bujard, H., Fishman, G.I., and Conklin, B.R. 1999. Conditional expression and signaling of a specifically designed Gi-coupled receptor in transgenic mice. Nat. Biotechnol. 17: 165-169.

Rogan, P.K., Faux, B.M., and Schneider, T.D. 1998. Information analysis of human splice site mutations. Hum. Mutat. 12: $153-171$.

Scrable, H. and Stambrook, P.J. 1997. Activation of the lac repressor in the transgenic mouse. Genetics 147: 297-304.

Shin, M.K., Levorse, J.M., Ingram, R.S., and Tilghman, S.M. 1999. The temporal requirement for endothelin receptor-B signalling during neural crest development. Nature 402: 496-501.

Shockett, P., Difilippantonio, M., Hellman, N., and Schatz, D.G. 1995. A modified tetracycline-regulated system provides autoregulatory, inducible gene expression in cultured cells and transgenic mice. Proc. Natl. Acad. Sci. 92: 65226526.

Swain, J.L., Stewart, T.A., and Leder, P. 1987. Parental legacy determines methylation and expression of an autosomal transgene: A molecular mechanism for parental imprinting. Cell 50: 719-727.

Tichelaar, J.W., Lu, W., and Whitsett, J.A. 2000. Conditional expression of fibroblast growth factor-7 in the developing and mature lung. J. Biol. Chem. 275: 11858-11864.

Tremblay, P., Meiner, Z., Galou, M., Heinrich, C., Petromilli, C., Lisse, T., Cayetano, J., Torchia, M., Mobley, W., Bujard, H., et al. 1998. Doxycycline control of prion protein transgene expression modulates prion disease in mice. Proc. Nat1. Acad. Sci. 95: 12580-12585.

Woychik, R.P., Camper, S.A., Lyons, R.H., Horowitz, S., Goodwin, E.C., and Rottman, F.M. 1982. Cloning and nucleotide sequencing of the bovine growth hormone gene. Nucleic Acids Res. 10: 7197-7210.

Wyborski, D.L., DuCoeur, L.C., and Short, J.M. 1996. Parameters affecting the use of the lac repressor system in eukaryotic cells and transgenic animals. Environ. Mol. Mutagen. 28: 447-458.

Xie, W., Chow, L.T., Paterson, A.J., Chin, E., and Kudlow, J.E. 1999. Conditional expression of the ErbB2 oncogene elicits reversible hyperplasia in stratified epithelia and up-regulation of TGFalpha expression in transgenic mice. Oncogene 18: 3593-3607.

Yamamoto, A., Lucas, J.J., and Hen, R. 2000. Reversal of neuropathology and motor dysfunction in a conditional model of Huntington's disease. Cell 101: 57-66.
Yokoyama, T., Silversides, D.W., Waymire, K.G., Kwon, B.S. Takeuchi, T., and Overbeek, P.A. 1990. Conserved cysteine to serine mutation in tyrosinase is responsible for the classical albino mutation in laboratory mice. Nucleic Acids Res. 18: 7293-7298.

Zuker, M., Jaeger, J.A., and Turner, D.H. 1991. A comparison of optimal and suboptimal RNA secondary structures predicted by free energy minimization with structures determined by phylogenetic comparison. Nucleic Acids Res. 19: $2707-2714$. 


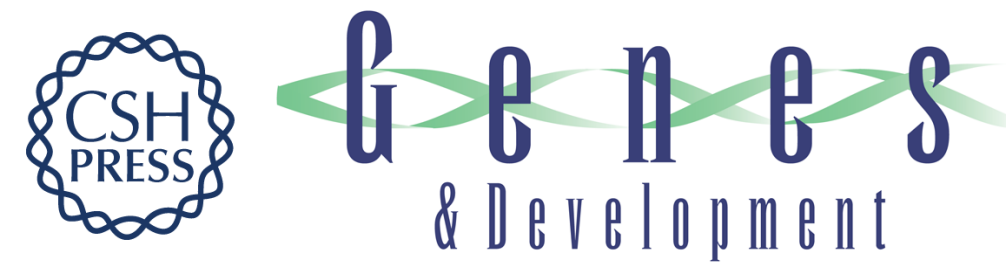

\section{The lac operator-repressor system is functional in the mouse}

Carolyn A. Cronin, Wendy Gluba and Heidi Scrable

Genes Dev. 2001, 15:

Access the most recent version at doi:10.1101/gad.892001

References This article cites 38 articles, 12 of which can be accessed free at: http://genesdev.cshlp.org/content/15/12/1506.full.html\#ref-list-1

License

Email Alerting Receive free email alerts when new articles cite this article - sign up in the box at the top Service right corner of the article or click here.

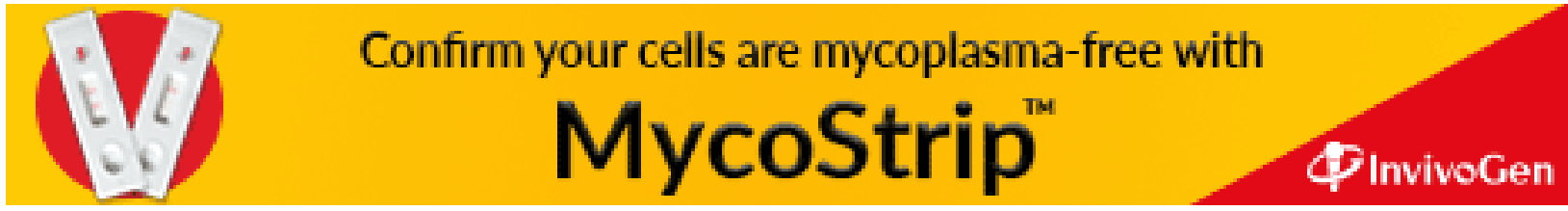

